\title{
Roger-Yves Roche, Photofictions. Perec, Modiano, Duras, Goldschmidt, Barthes
}

\section{Gian Luigi Di Bernardini}

\section{(2) OpenEdition}

1 Journals

\section{Edizione digitale}

URL: http://journals.openedition.org/studifrancesi/6102

DOI: 10.4000/studifrancesi.6102

ISSN: 2421-5856

\section{Editore}

Rosenberg \& Sellier

\section{Edizione cartacea}

Data di pubblicazione: 1 mai 2011

Paginazione: 215

ISSN: 0039-2944

\section{Notizia bibliografica digitale}

Gian Luigi Di Bernardini, «Roger-Yves Roche, Photofictions. Perec, Modiano, Duras, Goldschmidt, Barthes», Studi Francesi [Online], 163 (LV | I) | 2011, online dal 30 novembre 2015, consultato il 09 janvier 2021. URL: http://journals.openedition.org/studifrancesi/6102 ; DOI: https://doi.org/10.4000/ studifrancesi.6102

Questo documento è stato generato automaticamente il 9 janvier 2021.

\section{(c)}

Studi Francesi è distribuita con Licenza Creative Commons Attribuzione - Non commerciale - Non opere derivate 4.0 Internazionale. 


\title{
Roger-Yves Roche, Photofictions. Perec, Modiano, Duras, Goldschmidt, Barthes
}

\author{
Gian Luigi Di Bernardini
}

\section{NOTIZIA}

ROGER YVES ROCHE, Photofictions. Perec, Modiano, Duras, Goldschmidt, Barthes, Villeneuve d'Ascq, Presses Universitaires du Septentrion, 2009, pp. 315.

1 Pubblicazione di una tesi di dottorato discussa all'Università di Lyon 2, Photofictions esplora il rapporto tra narrazione e fotografia all'interno di un corpus non enorme, ma abbastanza variegato, quello costituito dagli autori annunciati dal titolo. $W$ ou le souvenir d'enfance (Perec), Chien de printemps (Modiano), L'Amant (Duras), Un jardin en Allemagne (Gold-

schmidt) et Chambre claire (Barthes) hanno in comune, agli occhi dell'autore, non tanto delle strutture narrative, quanto il tema della fotografia, che ne costituisce uno dei principi originari. Tramite una prosa informale - a tratti personalistica - e una griglia critica eclettica che include nozioni narratologiche di base, psicanalisi di orientamento lacaniano e altre, l'A. compie un itinerario attraverso i cinque testi indicati, a cui dedica monograficamente i capitoli in cui si articola il suo studio. Certamente suggestivo per chi volesse avvicinarsi a questa materia dal punto di vista della creazione, lo studio di Roche appare purtroppo non completamente solido dal punto di vista metodologico, data soprattutto l'insufficiente distinzione teorica tra testo narrativo alla prima persona e testo autobiografico vero e proprio. 